\title{
Resource Resurgence from COVID-19 Waste via Pyrolysis: a Circular Economy Approach
}

\author{
Biswajit Debnath $^{1,2} \cdot$ Shiladitya Ghosh ${ }^{3} \cdot$ Neelanjan Dutta $^{4}$ (D
}

Received: 28 May 2021 / Accepted: 11 August 2021 / Published online: 23 August 2021

(C) The Author(s), under exclusive licence to Springer Nature Switzerland AG 2021

\begin{abstract}
Since the end of 2019, COVID-19 pandemic has affected 220 countries and currently majority of the world is facing the wrath of the second wave. One of the outcomes of the ongoing pandemic is the generation of huge amount of solid polymeric "COVID-waste" comprising medical waste, personal protective equipment (PPE) waste, packaging waste, and other household waste with potential infectious components residing on it. Thermochemical route is the preferred treatment and effective way of disposal of such infectious polymeric waste. Typically, incineration is employed to ensure complete destruction of the pathogens which is not a resource-efficient method. Pyrolysis is a sustainable alternative which can handle the present COVID-waste stream in short-term and long-term yielding valuable fuel and material products. Recently published literature in this avenue have clearly shown the versatility of this technology in efficiently handling both mono and mixed stream of polymers. Based on facts, we propose a resource resurgence framework that utilizes pyrolysis as the core conversion route for effectively handling COVID-waste streams. Our framework suggests how these plants can be operational and helpful in generation of revenue in post-pandemic times as well. We expect that the conscientious adoption of pyrolysis will certainly lead us towards a circular economy paradigm.
\end{abstract}

Keywords COVID-19 · COVID-waste · Resource recovery · Pyrolysis · Circular economy · Sustainability

Neelanjan Dutta

neel2job@gmail.com

1 Chemical Engineering Department, Jadavpur University, Kolkata 700032, India

2 Department of Mathematics, ASTUTE, Aston University, B47ET, Birmingham, UK

3 Department of Food Technology, Guru Nanak Institute of Technology, Kolkata 700114, India

4 Department of Civil Engineering, NIT Sikkim, Sikkim, India 


\section{Introduction}

Outbreak of the terribly uncontrolled menacing pandemic COVID-19 caused due to the Severe Acute Respiratory Syndrome Coronavirus version 2 (SARS-CoV-2), has affected 220 countries and territories globally, causing 169,648,062 confirmed cases of infection and 3,525,426 confirmed deaths, as of 28th May 2021 [1, 2]. In the beginning months of 2020, a state of emergency was announced worldwide and imposed forthwith by World Health Organisation (WHO). As the primary measure of defence in an absolutely cureless situation, WHO has urged public health authorities in the respective affected countries to contain the spread of the virus within social spheres as small as possible to disrupt the chain of transmission of the outbreak. The virus transmits through micro/macro droplets produced during sneezing or coughing by an infected human [3]. Personal protective equipment (PPE) such as masks, gloves, PPE wearable kits, face shields, and personal hygiene products like alcohol-based sanitizers and surface sterilizers are the primary protections and commodities that were promptly put to compulsory use by the non-homebound people to minimize the risk of infection. This led to a sudden and enormous upsurge in the use of PPEs, majorly in the medical and human transport sectors. Fast forward to May 2021, some vaccines have surfaced such as BNT162b2 by Pfizer-BioNTech, Moderna by AstraZeneca, and COVISHIELD by Serum Institute of India [4-6]. Mass vaccination is slowly taking pace and amidst this, the world is experiencing the tsunami of the second wave, with countries like India being highly affected [7]. These breakthroughs in vaccine development are commendable but recent concerns have emerged with the efficacy related to mutated variations of the virus [8].

Despite all these, the continual use and demand for the PPE are increasing exponentially. As a result of their majorly "single-use" nature, the used and disposed PPEs are adding up to the ever-growing piles of complex anthropogenic solid waste. The overall composition of the solid waste stream has changed strikingly during this pandemic situation. Fear and anxiety have driven unnecessary stockpiling of food and groceries due to nationwide imposition of lockdown and consequent uncertainties have significantly altered the food waste generation dynamics. Considering the dry waste only, several used masks, gloves, PPE, empty sanitizer bottles, used tissue papers, and lots of packaging waste have increased in a typical "urban" waste stream generated in the metros and cities [9]. Another contributor to the rise in the quantity of packaging waste is due to a steep increase in e-commerce shopping, which has become a habit during the lockdown periods and to some extent, fear of contracting the COVID-19 virus [10]. On the embarkment of the COVID-19, medical waste generation reached up to 240 tons per day, in Wuhan city, China [11], whereas there was a $30 \%$ increase in medical waste generation in Malaysia by March 2020 [12]. To keep things simple, we term these infectious wastes as "COVID-waste" that includes medical waste, PPE waste, and other household waste with potential infectious components including discarded packaging waste. According to Prata et al. [13], the global monthly demand of gloves was almost 65 billion whereas for facemasks it was 129 billion to tackle COVID-19. The daily usage of facemasks has been estimated to be 7 billion per day [1,2]. As estimated by Hantoko et al. [14], North America generated nearly 72 kilotons of medical waste; followed by Europe, Asia, and South America with 70 kilotons, 55.6 kilotons, and 37 kilotons respectively, whereas Africa and Oceania are generating least amount of medical waste with 8.3kilotons and 0.12 kilotons respectively, based on facemasks only. The demand in PPE kits is projected to increase by $40 \%$ due to COVID-19 by WHO [15]. This article presents discussions on the ongoing thermochemical management efforts of COVID-waste, specifically focusing on conversion 
through pyrolysis and established a framework for highlighting the resource resurgence potential from the perspective of circular economy.

\section{Current Scenario of COVID-waste Generation}

The rapidly changing composition is not only dictating a paradigm shift for the solid waste management (SWM) industry but also indicating the probability of cross-contamination-contraction. The extremely infectious SARS-CoV-2 virus can persist in surfaces of cardboard, plastic, and metals for hours to days (as long as 9-day survival is reported) $[16,17]$. Hence, open dumping of COVID-waste carelessly will directly lead to high health risk of ground-level workers, especially in developing nations where rag pickers and waste collectors are not well aware of the viral contraction and are not equipped with PPEs themselves. There are several cases where workers in SWM facilities have tested COVID positive due to cross-contamination, an un-dismissible source of which may be the solid wastes [18]. This way, the medical and domestic fractions of the Covid-induced solid wastes produced globally are posing an ugly threat to the environment. This biohazard-laden plastic waste must be treated through a green route to free the environment from this burden in an eco-friendly manner and abiding by the global agenda of circular economy to contribute to sustainable waste management practices [19].

The commonly practiced plastic recycling and recovery methods were also affected by excessive PPE usage due to the COVID-19 pandemic, which is strongly boosting environmental pollution. As the PPEs include plastics as key constituents, the disposal of them without being recycled enhances the number of hazardous pollutants such as dioxins and toxic metals in the environment [15]. Due to the fast change of composition and characteristics of the generated waste, authorities are finding it difficult to cope up as the built infrastructures are not yet fully adapted and upscaled to efficiently handle such huge volume of PPE waste [20]. The wrath of the second wave of the ongoing pandemic has increased the generation of packaging materials and other medical things. The generation rate is expected to increase by $44.8 \%$ and $13.2 \%$ respectively due to higher demand of PPE kits and online food and essentials delivery [14]. In the healthcare sector, the demand of different commodities such as face shields, gloves, trash bags, and masks also increases the demand of different types of polymers such as polypropylene (PP), polyvinylchloride (PVC), and polyethylene terephthalate (PET) [13] which are also creating huge amount of plastic waste. Additionally, with the second wave, the demands of online grocery and food delivery services have increased. While the business giants are trying to seize the opportunity, the resulting waste streams are contributing to more and more COVID-waste.

\section{Available Practices for COVID-waste Management}

COVID-waste is infectious and bio-hazardous which needs to be disposed in a controlled environment of thermal treatment to destroy any living pathogen [16]. As the volume of waste surges up, existing capacity of waste treatment may not be enough, which will call for new facility establishment. An intelligent alternative is to utilize the existing MSW incinerators [14]. As proposed by United Nation Environment Programme (UNEP), steam sterilization and microwaving are the two most preferred technologies whereas the incineration of different 
categories are the secondary preferred [21]. Incineration does kill the pathogens and ensures that all toxic compounds are completely decomposed [22]. However, it is neither resource-efficient nor an eco-friendly technology. In developing countries like India, the increasing amount of packaging waste plastics such as polypropylene (PP), low-density polyethylene (LDPE), high-density polyethylene (HDPE), polyethylene terephthalate (PET), and polystyrene (PS) are creating massive pressure in open dumping yards and landfill sites. Discarded materials including contaminated face masks, gloves, and PPEs can aggravate environmental and health problems, particularly in countries like India, where the solid waste management system is still in the developing phase and yet to attain a fully dedicated stage within the whole chain of waste disposal to recycling.

Biodegradation of plastic waste is still a lingering challenge and only few early laboratory scale reports are available; hence, it cannot be adopted as a measure to treat and manage the highly recalcitrant COVID-waste. The most common approach to the present COVID-waste stream is to incinerate (combustion) the waste. Regarding the ease of operation, incineration is used as an "on-site" treatment of the COVID-waste, which is not so easy with other options like land filling. However, incineration is not a resource-efficient approach of waste management, as it is a route for direct destruction not recovery/recycling. Incineration is also adversely criticized for its huge carbon footprint produced from any type of solid waste (biomass and plastic) being combusted. Keeping in view the huge volume of the COVID-wastes, incineration should be deemed unsuitable as a primary option for treatment.

\section{Pyrolysis: a Promising Resource Resurgence Route for COVID-waste}

The joint agenda of implementing circular economy and sustainability in all future waste management systems calls for an efficient and suitable technology for COVID-waste handling $[23,24]$. Pyrolysis will serve as an alternative and arguably a sustainable technology to handle the present COVID-waste stream in short term and long term. Compared to incineration, pyrolysis is reported to be an eco-friendlier and resource-efficient process [25]. As a well-known green engineering approach, pyrolysis has long been adopted for recycling multiple types of solid waste including both biomass and plastic wastes [26-29]. Definitively, pyrolysis is the decomposition of feedstock in the absence of oxygen, which produces useful products, i.e. pyro-liquid, pyro-gas, and pyro-char or solid residue. Despite production of solid, liquid, and gaseous products, pyrolysis is majorly used for production of the "liquid oil part". Due to the usefulness of all the products and their collection for further use, unlike incineration, no product stream is directly open to the environment, which makes it a green process. It is reported by multiple previous studies that oil fraction reaches the maximum among all pyro-products when plastic or synthetic polymeric materials are used as feedstock [30, 31]. Operating temperature of pyrolysis plays the key role in the yield of maximum liquid or gas via the pyrolysis process, having a typical range of $623-873 \mathrm{~K}$. Configuration of the pyrolysis reactor and use of catalyst also have pronounced effects and need to be considered for better product yield [32]. Different kinds of plastic wastes, including a considerable amount of packaging plastics, being produced during this pandemic period, can be directly converted into fuel via pyrolysis without segregation. It is a very important fact for the COVID-waste that at their site of generation they are appearing as a relatively "source segregated" waste, due to the presence of contagious virus, which makes it un-mixable with other wastes. Segregated waste is always best for maximum resource recovery [25]. Many researchers confirm that 
pyrolysis of waste plastics yields significant quantity of oil (more than $50 \%$ wt. of feedstock) $[33,31]$. Hence, it is very well documented that pyrolysis process is considered as an effective and eco-friendly route for handling and converting the plastic or polymeric wastes to useful products since a long time. Therefore, in the context of the present article, the experimental case studies using COVID-19-induced polymeric wastes having similar composition as the pyrolysis feedstocks have been selectively highlighted to indicate its adoption as an efficient treatment technology. In Table 1, the information from latest articles reporting experimental studies on the pyrolysis of the polymeric wastes generated at excessively high rates during the outbreak of COVID-19 pandemic are presented. The effectiveness of pyrolysis process in different countries of the world for sustainable disposal of COVID-19 wastes along with recovery of valuable resources is tabulated. From the data represented in Table 1, it can be observed that a good quantity of liquid fuel rich in several hydrocarbon compounds was obtained from the pyrolysis of different polymeric wastes in the form of pyro-oil, which can be used as an alternative source of energy as a blend-in additive. The pyro-gas is also identified as an energy-rich product of pyrolysis.

However, use of catalyst may help to bring down the optimum temperature required for the pyrolysis process. There are specific effects of temperature as well as the catalyst on the product distribution [32]. Fine-tuning of these factors controls the percentage of aromatics and other desired chemicals in the pyro-oil and its fuel value (calorific value or higher heating value). Over the last decade, numerous research articles investigated and reported effect of several parameters of pyrolysis of different types of polymeric plastics (PP, LDPE, HDPE, PET, and PS) on the production of pyro-oil [30, 31, 33, 39, 40]). This will drive the adoption of pyrolysis as an efficient COVID-waste management and recycling method and construction of dedicated pyrolysis plants for the said purpose. The generated pyro-oil are used as an alternative fuel in gas turbines, generators, and boiler systems [25]. The fuel value of obtained distilled pyro-oil of packaging waste (PP, LDPE, and HDPE) was close to diesel with long hydrocarbon chains $(>\mathrm{C} 20)$ which confirms the robustness of the technology [41]. The gaseous or non-condensable part which evolved due to pyrolysis can be fed back for partial

Table 1 Resource recovery from polymeric waste materials generated during COVID-19 pandemic using pyrolysis

\begin{tabular}{|c|c|c|c|c|c|c|}
\hline $\begin{array}{l}\text { Sl. } \\
\text { no. }\end{array}$ & $\begin{array}{l}\text { Type of waste } \\
\text { materials }\end{array}$ & $\begin{array}{l}\text { Polymer } \\
\text { type }\end{array}$ & $\begin{array}{l}\text { Pyrolysis } \\
\text { temperature } \\
(\mathrm{K})\end{array}$ & Resource recovery & Country & References \\
\hline 1 & $\begin{array}{l}\text { Face mask, PPE } \\
\text { kits, packaging } \\
\text { materials }\end{array}$ & PP & 723 & $\begin{array}{l}92.3 \% \text { oil, } 4.1 \% \text { gas, and } 3.6 \% \\
\text { char }\end{array}$ & India & [34] \\
\hline 2. & 3-ply face mask & PP & $678-783$ & $\begin{array}{l}\text { 96.6\% volatiles, chemical } \\
\text { compounds, including } \\
\text { pentane, } \\
\text { 2,4-dimethyl-1-heptene }\end{array}$ & $\begin{array}{l}\text { Lithuania, } \\
\text { Russia } \\
\text { \& Egypt }\end{array}$ & {$[35]$} \\
\hline 3. & Waste face mask & & 823 & $\begin{array}{l}80.7 \% \text { oil yield. with HY zeolite } \\
\text { catalyst } 67 \% \text { higher BTEX } \\
\text { yield. }\end{array}$ & Korea & {$[36]$} \\
\hline 4. & $\begin{array}{l}\text { Disposable face } \\
\text { mask }\end{array}$ & PP \& PE & 873 & $\begin{array}{l}\text { Syngas and } \mathrm{C} 1-2 \text { hydrocarbons. } \\
\mathrm{Ni} / \mathrm{SiO}_{2} \text { catalyst expedites } \mathrm{H}_{2} \\
\text { and } \mathrm{CH}_{4} \text { generation. }\end{array}$ & $\begin{array}{c}\text { Korea and } \\
\text { China }\end{array}$ & {$[37]$} \\
\hline 5. & $\begin{array}{l}\text { Mix of gloves } \\
\text { and face mask }\end{array}$ & $\begin{array}{l}\mathrm{PP}+ \\
\quad \mathrm{PVC}\end{array}$ & 673 & $\begin{array}{l}75 \% \text { oil, } 15 \% \text { gas, and } 10 \% \\
\text { char. }\end{array}$ & Ethiopia & [38] \\
\hline
\end{tabular}


heating of the reactor. The final flue gas can be controlled using standard pollution control equipment. The residue or the char is a suitable feedstock for the preparation of sorbent material as well as nanostructured carbon materials [42, 43].

\section{Proposed Resource Resurgence Framework for COVID-waste Management}

On the basis of the foregoing facts, we propose a resource resurgence framework that utilizes pyrolysis as the core conversion route for effectively handling COVID-waste streams. We assume a significant amount of waste is source segregated. As shown in Figure 1, waste collection from households and curb side is executed by the trained Urban Local Bodies (ULB). Biomedical waste management companies carry out the collection from hospitals through proper channel maintaining all safety protocols administered by WHO. Collected waste containing synthetic polymeric fraction is fed to the optimally designed pyrolysis process and produces pyro-oil, pyro-char, and pyro-gas through the thermochemical conversion. We recommend in-situ utilization of pyro-gas in the reactor itself, while the other two products can be helpful in revenue generation. A treatment, storage, and disposal facility (TSDF) handles any hazardous fraction that is generated as side stream from the core unit of process plant. The framework is also applicable for COVID-waste collected from public places, eateries, and shops as well those that generate a substantial quantity of disposables and other polymeric waste. This will allow the resource to be circulated along the value chain in a "closed flow", conforming to the circular economy principles [44]. In the post-pandemic time, the plant will continue to serve as a primary waste management facility for treating all other synthetic polymeric city-wastes generated in future.

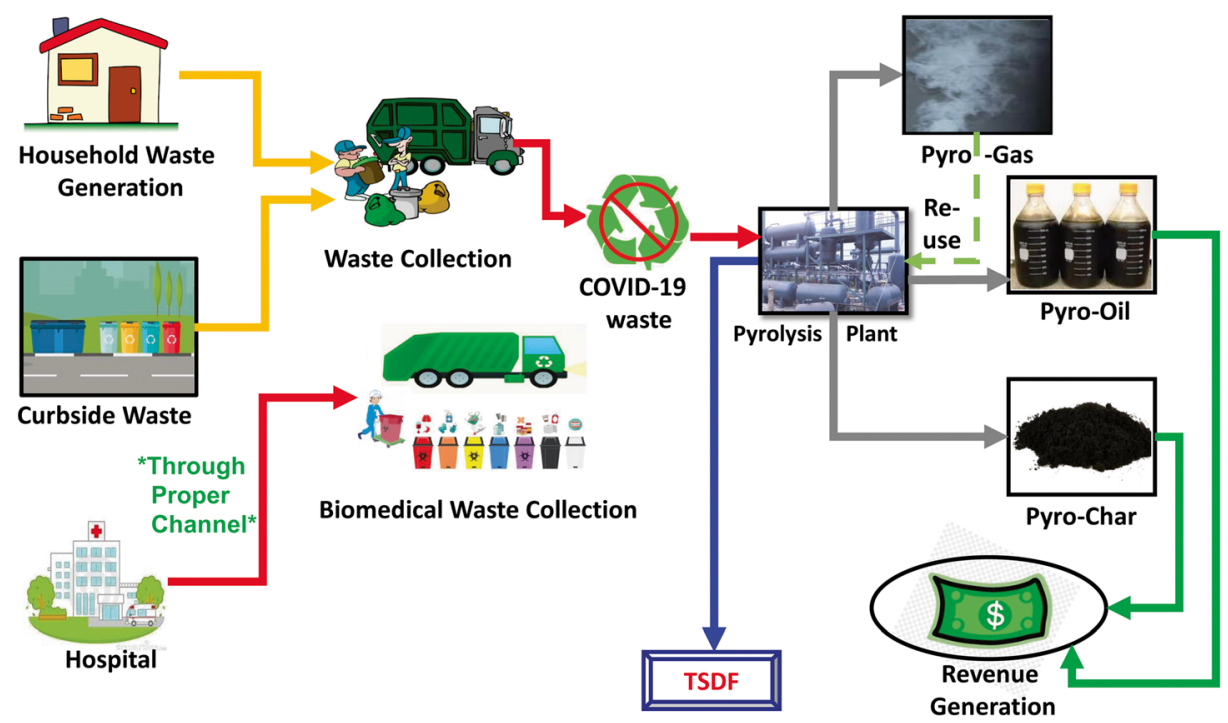

Fig. 1 Suggestive framework showing waste management scheme utilizing pyrolysis as a potential technology for resource resurgence. Waste collected from households, curb side, and hospitals is subjected to pyrolysis. Pyro-oil and pyro-char can be used for revenue generation while there is in situ utilization of the pyro-gas for heating purpose 
Pyrolysis is slowly getting momentum in the large-scale processing of plastics to fuel scenario. In India, there are a few pilot plants converting plastics to fuel. Rudra Environmental Solutions India Limited is one of the benchmark pyrolysis plants in Pune, India. The plant was set up in 2010 with a capacity of $50 \mathrm{~kg}$ per day and now a third-generation plant is operating since 2016 with a capacity of $500 \mathrm{~kg}$ per day [45]. A group of researchers at IIT Delhi have patented the technology for conversation of plastics to fuel range products [46] They are planning to use the installed laboratory facility for treatment plastics collected by South Delhi Municipal Corporation (SDMC) (IIT [47]). A future full-scale plant is expected down the line. Pyrolysis has also been tested with multi-layered packaging (MLP) waste using commercial zeolite catalyst in pilot scale, which suggests that biaxial oriented polypropylene MLPs can produce more than $70 \%$ oil [48]. Jectec, a Japan-based company, is also implementing pyrolysis for treatment of cable wires [49]. Sparta group in Canada is also implementing pyrolysis for converting non-recyclable plastics into fuel [50]. The proposed framework (Figure 1) can be extended towards developing benchmark practices considering other non-COVID-waste streams such as plastic waste, e-waste, agro-waste, and municipal waste.

Implementation of the concept of circular economy begun at various industries, as they are identified as the largest producers of solid waste in a global scenario [44]. In the developing countries, it is still at the initial level of implementation, due to less awareness. It is expected that waste-less industries will rise with circular economy as a guiding principle, which will ultimately lead towards sustainable development [51]. As discussed earlier, the proposed framework illustrated in Figure 1 may serve as a "prototype" for designing models of resource recovery plants handling multiple wastes including COVID-19 waste as pyrolysis feedstocks in accordance with the circular economy criterion. The discussions presented in the preceding sections have highlighted the resource potential of the COVID-waste and its recovery through pyrolysis process following circular economy. Further increase in circularity is possible with higher public awareness and better policy control and monitoring at the national level. This will facilitate realization and preservation of resource value of the COVID-waste by avoiding mixing and channelization of feedstock towards the processing plant as much as possible. Pyrolysis, being a resource-efficient process, is expected that in near future, the demand for pyrolysis plant as COVID-waste handling and valorization units will only increase. These units can serve as a common resource recovery facility (CRRF) for waste coming from multiple waste-sorting facilities, similar to common effluent treatment plants. Hence, this is not a one-stop solution, rather a beginning towards closing the loop.

\section{Conclusion}

In recent times, the whole world is confronting numerous challenges for revitalizing the economic breakdown caused due to the pandemic. The proposed resource resurgence strategy of utilizing pyrolysis as the core waste management route (for COVID-waste and other wastes) will not only reduce the extreme environmental burden but also will ensure resource circulation, thereby promoting circular economy. Pyrolysis will efficiently contribute towards creating a sustainable and resource-efficient treatment technology via the production of liquid fuel from various waste plastics and PPE kits. A balanced socio-economic growth, along with the environmental benefits, will help to reduce the future crisis to some extent. Researchers, private companies, entrepreneurs, and policymakers should come forward with joint effort to solve the issue of waste reduction by considering the current pandemic as an opportunity of 
developing new sustainable business models, rather than treating it just as an environmental concern. Development of COVID-waste treatment and valorization frameworks as the one proposed in this article will instigate the awareness and deployment of circular economy approach in the present and post-COVID era. We expect that the conscientious adoption of sustainable technologies, such as pyrolysis, will affirmatively lead us towards a circular economy paradigm.

Acknowledgements The authors acknowledge the help and inputs received from Prof. Anirban Gupta, IIEST Shibpur, during the preparation of this manuscript. Additionally, inputs from Dr. Saswati Gharami, Jadavpur University, were insightful for the authors.

Author Contribution Led by BD, and co-conceptualized by ND, the foundation was substantiated by SG. Data mining was carried out by all the authors. Resource recovery framework based on circular economy concept was developed by BD with analysis and inputs from SG and ND. All authors have read and agreed to this version of the manuscript.

\section{Data Availability N/A}

Code Availability No codes were used.

\section{Declarations}

Conflict of Interest The authors declare no competing interests.

Disclaimer Any opinions, findings, and conclusions expressed in this material are those of the author(s) and do not necessarily reflect the views of the affiliated universities of the authors.

\section{References}

1. Woldometer, (2021a). Covid-19 coronavirus pandemic. Accessed 2021, January 21. https://www. worldometers.info/coronavirus/.

2. Woldometer, (2021b). Covid-19 coronavirus pandemic. Accessed 2021, May 28. https://www. worldometers.info/coronavirus/

3. Spinelli A, Pellino G (2020) COVID-19 pandemic: perspectives on an unfolding crisis. Journal of British Surgery 107(7):785-787

4. Tyagi K, Ghosh A, Dipti NAIR, Pyrolysis K, Bhandari PS, Ansari IA, Misra A (2021) Breakthrough COVID19 infections after vaccinations in healthcare and other workers in a chronic care medical facility in New Delhi, India. Clinical Research \& Reviews, Diabetes \& Metabolic Syndrome

5. Cdc.gov. (2021). Different COVID-19 vaccines. Centers for Disease Control and Prevention. https://www. cdc.gov/coronavirus/2019-ncov/vaccines/different-vaccines.html. Accessed 14 May 2021

6. Seruminstitute.com (2021). Serum Institute of India - ChAdOx1 nCoV- 19 Corona Virus Vaccine (Recombinant) - COVISHIELD. Seruminstitute.com. https://www.seruminstitute.com/product_covishield. php. Accessed 14 May 2021

7. The Lancet (2021) India's COVID-19 emergency. Lancet 397(10286):1683

8. Possas, C., de Souza Antunes, A. M., de Oliveira, A. M., de Souza Mendes, C. D. U., Ramos, M. P., Schumacher, S. D. O. R., \& Homma, A. (2021). Vaccine innovation for pandemic preparedness: patent landscape, global sustainability, and circular bioeconomy in post-COVID-19 era. Circular Economy and Sustainability, 1-23

9. Hantoko D, Li X, Pariatamby A, Yoshikawa K, Horttanainen M, Yan M (2021) Challenges and practices on waste management and disposal during COVID-19 pandemic. J Environ Manag 286:112140

10. Leal Filho W, Voronova V, Kloga M, Paço A, Minhas A, Salvia AL et al (2021) COVID-19 and waste production in households: a trend analysis. Sci Total Environ 777:145997 
11. Tang, W. (2020). The medical waste related to COVID-2019 is cleaned up every day - the medical waste treatment market needs to be standardised. 21st Century Business Herald. http://www.21jingji.com/2020/312/xNMDEzODFfMTU0MjIxNQ.html. Accessed 14 May 2021.

12. Agamuthu P, Barasarathi J (2020) Clinical waste management under COVID-19 scenario in Malaysia. Waste Manag Res 39(1):18-26. https://doi.org/10.1177/0734242X20959701

13. Prata JC, Silva AL, Walker TR, Duarte AC, Rocha-Santos T (2020) COVID-19 pandemic repercussions on the use and management of plastics. Environ Sci Technol 54(13):7760-7765

14. Hantoko, D., Li, X., Pariatamby, A., Yoshikawa, K., Horttanainen, M., Yan, M. (2021) Challenges and practices on waste management and disposal during COVID-19 pandemic. Journal of Environmental Management 286112140-10.1016/j.jenvman.2021.112140

15. Singh N, Tang Y, Ogunseitan OA (2020) Environmentally sustainable management of used personal protective equipment. Environ Sci Technol 54(14):8500-8502

16. Kampf G, Todt D, Pfaender S, Steinmann E (2020) Persistence of coronaviruses on inanimate surfaces and their inactivation with biocidal agents. J Hosp Infect 104(3):246-251

17. Van Doremalen N, Bushmaker T, Morris DH, Holbrook MG, Gamble A, Williamson BN, Tamin A, Harcourt JL, Thornburg NJ, Gerber SI, Lloyd-Smith JO (2020) Aerosol and surface stability of SARS-CoV2 as compared with SARS-CoV-1. N Engl J Med 382(16):1564-1567

18. Mallapur, C. (2020). Indian households' ineffective waste management is putting sanitation workers at risk of Covid-19. Scroll.in. https://scroll.in/article/958711/indian-households-ineffective-waste-management-isputting-sanitation-workers-at-risk-of-covid-19. Accessed 14 May 2021

19. Antoniadou M, Varzakas T, Tzoutzas I (2021) Circular economy in conjunction with treatment methodologies in the biomedical and dental waste sectors. Circ Econ Sust. https://doi.org/10.1007/s43615-02000001-0

20. Sarkodie, S. A., \& Owusu, P. A. (2020). Impact of COVID-19 pandemic on waste management. Environment, Development and Sustainability. doi:10.1007/s10668-020-00956-y

21. United Nations Environment Programme (UNEP), 2020. How to choose your waste management technology to treat COVID-19 waste. https:/wedocs.unep.org/bitstream/handle/20.500.11822/32778/FS3.pdf. .

22. World Health Organization (WHO), 2017. Safe management of wastes from health-care activities: a summary. https://apps.who.int/iris/bitstre am/handle/10665/259491/WHO-FWC-WSH-17.05-eng.pdf; jsessionid=77A8E6456068068F87A5FC473E3EC168? sequence $=1$. Accessed 14 May 2021

23. Nikolaou IE, Jones N, Stefanakis A (2021a) Circular economy and sustainability: the past, the present and the future directions. Circ Econ Sust 1:1-20. https://doi.org/10.1007/s43615-021-00030-3

24. Nikolaou IE, Jones N, Stefanakis A (2021b) Circular economy and sustainability: the past, the present and the directions. Circular Economy and Sustainability 1:1-20

25. Ghosh A, Debnath B, Ghosh SK, Das B, Sarkar JP (2018) Sustainability analysis of organic fraction of municipal solid waste conversion techniques for efficient resource recovery in India through case studies. Journal of Material Cycles and Waste Management 20(4):1969-1985

26. Dutta N, Gupta A (2021) An experimental study on conversion of high density polyethylene and polypropylene to liquid fuel. Clean Techn Environ Policy. https://doi.org/10.1007/s10098-021-02121-z

27. Ghosh S, Das S, Chowdhury R (2019) Effect of pre-pyrolysis biotreatment of banana pseudo-stem (BPS) using synergistic microbial consortium: role in deoxygenation and enhancement of yield of pyro-oil. Energy Convers Manag 195:114-124

28. Dash A, Kumar S, Singh RK (2015) Thermolysis of medical waste (Waste Syringe) to liquid fuel using semi batch reactor. Waste and biomass valorization 6(4):507-514

29. Shah J, Jan MR (2014) Thermo-catalytic pyrolysis of polystyrene in the presence of zinc bulk catalysts. J Taiwan Inst Chem Eng 45(5):2494-2500

30. Martynis, M., Mulyazmi, Winanda, E., \& Harahap, A. N. (2019). Thermal Pyrolysis of Polypropylene Plastic Waste into Liquid Fuel: Reactor Performance Evaluation. IOP Conference Series: Materials Science and Engineering, 543, 012047. doi:10.1088/1757-899x/543/1/012047

31. Osman AI, Farrell C, Al-Muhtaseb AH, Al-Fatesh AS, Harrison J, Rooney DW (2020) Pyrolysis kinetic modelling of abundant plastic waste (PET) and in-situ emission monitoring. Environ Sci Eur 32(1):1-12

32. Debnath B, Chowdhury R, Ghosh SK (2019) An analysis of e-waste recycling technologies from the chemical engineering perspective. In: In Waste Management and Resource Efficiency (pp. 879-888). Springer, Singapore

33. Honus, S., Kumagai, S., Fedorko, G., Molnár, V., \& Yoshioka, T. (2018). Pyrolysis gases produced from individual and mixed PE, PP, PS, PVC, and PET_Part I: Production and physical properties. Fuel, 221, 346-360. https://doi.org/10.1016/j.fuel.2018.02.074

34. Dharmaraj S, Ashokkumar V, Pandiyan R, Munawaroh HSH, Chew KW, Chen WH, Ngamcharussrivichai C (2021) Pyrolysis: an effective technique for degradation of COVID-19 medical wastes. Chemosphere 275:130092 
35. Yousef S, Eimontas J, Striūgas N, Abdelnaby MA (2021) Pyrolysis kinetic behaviour and TG-FTIR-GCMS analysis of coronavirus face masks. J Anal Appl Pyrolysis 156:105118

36. Lee SB, Lee J, Tsang YF, Kim YM, Jae J, Jung SC, Park YK (2021) Production of value-added aromatics from wasted COVID-19 mask via catalytic pyrolysis. Environ Pollut 283:117060

37. Jung S, Lee S, Dou X, Kwon EE (2021) Valorization of disposable COVID-19 mask through the thermochemical process. Chem Eng J 405:126658

38. Aragaw TA, Mekonnen BA (2021) Current plastics pollution threats due to COVID-19 and its possible mitigation techniques: a waste-to-energy conversion via Pyrolysis. Environmental Systems Research 10(1): $1-11$

39. Al-Salem SM, Lettieri P (2010) Kinetic study of high-density polyethylene (HDPE) pyrolysis. Chem Eng Res Des 88(12):1599-1606

40. Adeniyi AG, Ighalo JO (2020) Simulation of low density polyethylene (LDPE) pyrolysis and optimisation of pyro-oil yield. Int Polym Process 35(2):229-235

41. Das P, Tiwari P (2018) Valorization of packaging plastic waste by slow pyrolysis. Resour Conserv Recycl 128:69-77

42. Debnath B, Saha I, Mukherjee T, Mitra S, Das A, Das A (2021) Sorbents from waste materials: a circular economic approach. In: Sorbents Materials for Controlling Environmental Pollution (pp. 285-322). Elsevier

43. Mukherjee, A., Debnath, B., \& Ghosh, S. K. (2019). Carbon nanotubes as a resourceful product derived from waste plastic - a review. Waste Management and Resource Efficiency, 915-934

44. Halog, A., \& Anieke, S. (2021). A review of circular economy studies in developed countries and its potential adoption in developing countries. Circular Economy and Sustainability, 1-22

45. Rudraenvsolution.com. (2020). Retrieved 20 July 2021, from http://www.rudraenvsolution.com/images/ rudrainfo.pdf

46. Pant KK, Naik SN, \& Dwivedi U (2018) A process and two-step catalytic reactor system for the production of liquid hydrocarbons from plastic waste (Indian - Patent Application No.: 201811032378)

47. IIT Delhi. (2021). Retrieved 21 July 2021, from https://www.facebook.com/IITDelhi/posts/ 4135105469871145

48. Sivagami K, Divyapriya G, Selvaraj R, Madhiyazhagan P, Sriram N, Nambi I (2021) Catalytic pyrolysis of polyolefin and multilayer packaging based waste plastics: a pilot scale study. Process Saf Environ Prot 149: 497-506

49. Debnath B, Chowdhury R, Ghosh SK (2018) Sustainability of metal recovery from E-waste. Frontiers of environmental science \& engineering 12(6):1-12

50. Ellsworth, B. (2019). Canadian firm turns non-recyclable plastics to fuel. Retrieved 21 July 2021, from https://www.aa.com.tr/en/asia-pacific/canadian-firm-turns-non-recyclable-plastics-to-fuel/1556029\#: :text= TRENTON\%2C\%20Canada,fuel\%20the\%20company's\%20 truck\%20fleet.

51. Cecchin, A., Salomone, R., Deutz, P., Raggi, A., \& Cutaia, L. (2021). What is in a name? The rising star of the circular economy as a resource-related concept for sustainable development. Circular Economy and Sustainability, 1-15 